\title{
CONFIGURING INNOVATIVE SOCIETIES: THE CROSSVERGENT ROLE OF CULTURAL AND INSTITUTIONAL VARIETIES
}

\begin{abstract}
The study aims to explore why some societies are more innovative than others in hightechnology sectors. Following a crossvergence perspective, we generate nine causal conditions by accommodating both cultural and institutional varieties: uncertainty avoidance, masculinity, individualism and power distance as culture indicators, and union density, skill development, market capitalization to credit, prevalence of cluster and state dominance as institutional indicators. Applying the configurational approach, we conducted fuzzy-set qualitative comparative analysis (fsQCA) on Organisation for Economic Co-operation and Development (OECD) member countries. We confirm the equal importance of both cultural and institutional mechanisms as contributors to national innovativeness, and identify equifinal configurations of cultural and institutional varieties as leading to a high-tech society. The implication is that a society can adjust or develop various cultural and/or institutional conditions to maintain or create leadership in innovation.
\end{abstract}

Keywords: Innovation, Cultural Dimensions, Comparative Institutional Varieties, Crossvergence, Fuzzy Set Methods

Running head: Configuring innovative societies 


\section{Introduction}

Why are some societies more innovative than others in high-technology sectors? Two decades ago, a culturalist, Shane (1992), made a landmark attempt to answer this meaningful research question. Embracing Hofstede's (1980) culture dimension theory, Shane (1992, 1993, 1995) concluded that some societies might have a cultural comparative advantage in inventiveness, and the same cultural values (e.g., uncertainty acceptance, individualism and the lack of power distance) that operate on the national level also operate on the firm level, leading those companies and countries with innovative cultures to invent more than do others. Shane's empirical studies contribute in two aspects: establishing the relationship between national culture and innovation, and exploring the configurational nature of culture (cf., Efrat, 2014; Hofstede, 2006, 2011; Hofstede et al., 1990).

In contrast to culturalists, institutionalists argue for the importance of regulatory, political, and economic structures in contributing to building innovative societies. Given that a nation or state remains the primary unit in governing economic activities (Allen, 2012), scholars have employed a number of concepts and frameworks to describe the feature and form of an innovative society, such as "national innovation systems" (NIS) (Freeman, 1995; Lundvall, 2007; Rothberg, 1995; Samara et al., 2012), "national business systems” (Hotho, 2014; Whitley, 1992, 1999, 2007), "social systems of innovation and production" (Amable, 2003), or "varieties of capitalism" (Clausen, 2014; Hall and Soskice, 2001; Jackson and Deeg, 2008). In these frameworks, institutional characteristics are deemed as either antecedents or determinants individually, or as causal conditions together that lead to configurational solutions to enhancing innovation.

Nevertheless, the literatures on the cultural perspective and institutional perspective of national innovation performance have developed rather independently, and neither of the approaches has been supported by consistent empirical evidence. One reason might be that 
scholars tend to conflate culture and institutions in various ways. Culturalists claim that cultural difference is the root of institutional variations (e.g., Javidan et al., 2006). Institutionists argue that culture is under the conceptual umbrella of "institution". Various streams of institutional theories commonly treat culture - more specifically shared values and non-codified standards - as an important reflection of a country's informal institutions (Holmes et al., 2013; North, 1990; Peng et al., 2008). However, scholars subscribing to the crossvergence view (Ralston et al., 1997) suggest that in fact culture and institution co-evolve and affect each other in a pathdependent way (cf., Ralston, 2008; Witt, 2008) so as to create a unique set of managerial values in a country (Ralston et al., 1993). In light of these views, Taylor and Wilson (2012) called for research on the joint effect of culture and institutions on national innovation rates, because the effectiveness of institutions and cultural dimensions are conditional on each other.

Given that the logic linkages between cultural and institutional mechanisms and national innovation co-exist and are co-evolutionary, we follow a configurational approach for theory building, which has been increasingly adopted in business research (Crilly et al., 2012; Fiss, 2007, 2011; Misangyi and Acharya, 2014; Misangyi et al., 2016). In contrast to the variancebased approach, which aims to identify the deterministic condition under which the individual causal effect on the desired outcome is maximized, the configurational approach allows for equifinality and explores multiple causal pathways (or patterns) that lead to the same level of desired outcome (Fiss, 2007; Misangyi et al., 2016; Ragin, 2008). In our context, this approach enables us to capture various configurations of cultural and institutional varieties that work together to enhance national innovation outcome. Existing research has demonstrated the efficacy of the configurational approach for explaining complex social and organizational phenomena (e.g., Fiss, 2011; Misangyi and Acharya, 2014), as it acknowledges the interdependent nature of analytical units, where fit and competitive advantages frequently rest on the complementarities between multiple characteristics (e.g., Fiss, 2007, 2011). Porter (1990) 
argued that economic activities are embedded in social activities. Since national innovation is an important aspect of economic activities, the core objective and main contribution of this study is to address how "social glue" binds both cultural and institutional elements together to build an innovative society - "one of the major research questions in the social sciences today" (Witt and Redding, 2009: 859).

The remainder of this paper is organized as follows. Section 2 introduces the research background, and, briefly, both culture- and institution-based views on national innovation. Section 3 develops three major research propositions to be addressed by our data. Sections 4 and 5 detail research design and results, respectively. Section 6 brings the paper to a close with some concluding implication points and an overview of study limitations and avenues for future research.

\section{Literature Review}

\subsection{Hofstede's culture dimensions}

Culture is "the collective programming of the mind which distinguishes the members of one human group from another" (Hofstede, 1980: 21). In his watershed study, Hofstede (1980) examined four major culture dimensions, namely, uncertainty avoidance, masculinity, individualism, and power distance, which can be used to detail similarities and differences of systems of societal norms and values shared by major groups of the population in 40 societies.

Despite the emergence of other complementary works on culture (Schwartz, 1992; Trompenaars and Hampden-Turner, 1997), Hofstede's framework of four culture dimensions has shown high validity and reliability. Some major replications (e.g., Merritt, 2000; Shane, 1995), conducted decades after Hofstede's (1980) work, support the original findings and suggest that the culture dimensions are still relevant today. Most countries' cultures are enduring over time (cf. Inglehart and Baker, 2000), and the persistence of distinct cultural 
dimensions are found to change together, so that their relative positions remain stable (Hofstede et al., 2010).

Embracing Hofstede's culture dimension framework, Shane (1992, 1993, 1995) has conducted a number of empirical studies to provide evidence as to whether each of Hofestede's culture dimensions can have a significant impact on national innovation (see details in Appendix 1 - Part A). Inspired by Shane (1992, 1993, 1995), other culturists, such as Rinne and colleagues (2012) and Taylor and Wislson (2012), have further pursued more empirical evidence in a similar vein.

Despite the efforts of previous scholars, the literature is yet to reach a consensus on which of the cultural dimensions promote innovation and whether the effects of these dimensions are consistent and robust across countries and time periods. The link between certain cultural dimensions and innovation is not well-established at the national level and is contradictory to the theoretical predictions. As culturalists primarily focus on individual values and the willingness to innovate, one might argue that, for such willingness and motivation to transform to action, they need to be combined with certain ways of organizing economic activities that create an environment conducive to undertaking innovation.

\subsection{Comparative institutional perspective}

The comparative institutional perspective addresses differences in socio-economic organization between countries (Hall and Soskice, 2001; Whitley, 1992, 1999; Jackson and Deeg, 2008). An underlying assumption is that countries may differ noticeably in how economic activity is organized and controlled, regardless of the level of institutional development (Whitley, 1999; Hall and Soskice, 2001). Comparative institutional scholars have shown that well-developed economies that have similar institutional development levels differ considerably in the dominant type of firms, their organizational capabilities and interests, and 
their relations with other economic actors (Whitley, 1999, 2007). National institutional frameworks and policies influence the level of business-funded research and development (R\&D) and the technological competitiveness of firms in a country (Carlsson, 2006; Herrera and Nieto, 2008; Senker, 1996), leading to different patterns of innovative activities (Hall and Soskice, 2001). According to Hall and Soskice's (2001) framework, liberal market economies (LME) countries (e.g., the US) specialize in radical innovation, while coordinated market economies (CME) countries (e.g., Germany) focus more on incremental innovation.

A central feature of comparative institutional perspective is that institutions in different societal domains, such as education systems, financial systems and the nature of market relations, are considered to be reciprocally constituted and path-dependent (Hotho and Pedersen, 2012; Whitley, 1992, 1999; Hall and Soskice, 2001). Thus, in well-developed countries, the constituent dimensions of institutions develop in a mutually reinforcing and interdependent way (Hotho and Pedersen, 2012; Whitley, 1992, 1999; Hall and Soskice, 2001). According to Jackson and Deeg (2008: 557), institutions of well-developed countries generally form relatively stable and complementary configurations that help reproduce a distinctive economic logic, or particular "strategies, routine approaches to problems and shared decision rules that produce predictable patterns of behavior by actors within the system".

The present study focuses on five specific institutional dimensions in accordance with the comparative institutional framework developed by Whitley $(1998,1999)$, of which four dimensions are highlighted: the skill-development system, the characteristics of the financial system, the role assumed by the state, and the norms and values that resonate in work relations. Since the remaining dimension of "norms and values" largely refers to cultural indicators, we replace it with Hofstede's four cultural dimensions discussed above. Five specific indicators of institutional dimensions, namely, union density, skill development, market capitalization to credit, prevalence of clusters and state dominance, are detailed in Appendix 1 - Part B. 
Researchers have found evidence of the specificity of national business systems and have concluded that various institutional dimensions collectively produce distinct ways of economic coordination, in accordance with the complementary patterns posited by the comparative institutional perspective (Hotho, 2014; Schneider et al., 2010). Nevertheless, the results also point to a neglected fact that those countries sharing the combination of institutional conditions for achieving strong innovation performance apparently belong with the same cultural cluster (Hotho, 2014; Ronen and Shenkar, 2013). Whilst institutionalists have predominantly focused on the comparison of one business system with another (Whitley, 2000), there are cases where two countries with similar economic organization do not match in the level of innovation performance (Schneider et al., 2010). It appears that an institutional regime only predisposes an economy to specializing in one type of innovation but does not necessarily guarantee the production of such innovations (Akkermans et al., 2009). Little is known as to whether institutional regimes need to be complemented by certain cultural values to promote innovative activities, or whether culture and institutions are interdependently developed and mutually reinforced. Moreover, it is posited that the trend of globalization may reduce the sectorial specialization of the business system within established political boundaries, given the coevolution of multinational enterprises and local institutions and the acquisition of capabilities from abroad (Allen, 2012; Cantwell et al., 2010). Culturalists, in contrast, would suggest otherwise, because the immobility of the workforce across borders determines that the innovation performance of high-tech industries in particular will continue to be shaped by the home-country cultural setting. Only by taking into account the crossvergence of both culture and institutions on innovation patterns and performance can we solve these puzzles.

\section{Research Propositions}

Nine factors derived from the two distinguished but interconnected theoretical frameworks, namely, culture indicators (including (1) uncertainty avoidance, (2) masculinity, (3) 
individualism, (4) power distance, and institutional indicators, including (5) union density, (6) skill development, (7) market capitalization to credit, (8) prevalence of cluster and (9) state dominance) were identified above as elements of the configurations of the culture-institution mechanism of a society's innovation performance. Following the configurational approach of theory building (Crilly, 2011; Fiss, 2007, 2011), we posit that, rather than the independent effects of the identified factors, configurations of these factors are what drive societies to be innovative. We offer three propositions to guide the empirical analysis facilitated by the fsQCA technique (Crilly et al., 2012; Fiss, 2011; Ragin, 2008).

\subsection{Configuration as a joint causal effect}

The management literature has derived two different opinions as to why one particular society is more innovative than another, even when a comparison is made between advanced economies (e.g., Hotho, 2014; Rinne et al., 2012; Shane, 1992, 1993; Schneider et al., 2010). However, the two theoretical thoughts are not necessary mutually exclusive. Landes (2000: 2) strongly argued that, "if we learn anything from the history of economic development, it is that culture makes almost all the difference". Porter (2000: 14) agreed that "culture plays an unquestioned role in human behavior and progress". Chui, Lloyd and Kwok (2002) confirmed that cultural influences provide a foundation that shapes economic activities (e.g., corporate capital structure). Further, Redding (2005) contended that the relationship between national culture and economic success can be co-evolutionary. The development of the institutional perspective has also paid attention to the role of culture but it only treats culture dimensions in aggregate as one pillar or aspect of institutions (North, 1990; Peng et al., 2008). For instance, the comparative institutional perspective highlights the norms and values that resonate in work relations as one of four co-existing institutional dimensions (Whitley, 1998, 1999). Moreover, some institutionalists (e.g., Holmes et al., 2011; North, 1990; Peng et al., 2008) distinguish institutions as formal and informal, the latter referring to culture. 
Acknowledging that the significance of the competing theoretical angles does not necessarily make the theory itself more powerful in explaining the reality, the crossvergence view holders, such as Redding (2005), explicitly emphasize that the culture school underlies institutions. So do institutionalists. Javidan et al. (2006: 908) claim that the relationships between wealth, national culture and other institutions are "so intertwined that they cannot be easily isolated". Therefore, scholars (e.g., Ralston et al., 1997; Ralston, 2008; Witt, 2008) draw a conclusion that both institutional and cultural dimensions have an important influence on social matters. In particular, Witt and Redding (2009) combined both national cultures and institutional thinking to explain "the evolutionary trajectories of national business systems". Derived from the crossvergence perspective, and the fact that there is a lack of empirical evidence of joint casual effect of cultural and institutional varieties on national innovation, we propose our first research proposition:

Proposition 1. The effectiveness of national innovation requires the presence of both cultural and institutional mechanisms.

\subsection{Causal configuration equifinality}

A unique advantage of applying the configurational approach using the fsQCA technique is of capturing the feature of equifinality, which is a situation where "a system can reach the same final state from different initial conditions and by a variety of different paths" (Fiss, 2007:1181). As opposed to conventional econometric methods that tend to imply linearity, additive effects and unifinality, the configurational approach objects to the notion of an optimal solution and embraces nonlinearity and synergistic effects. Configurational equifinality emerges when organizations face multiple and sometimes conflicting functional demands that require prioritizing to obtain an achievable outcome level, and organizations differ in their functional prioritization, which leads to different structures that may generate the same or 
similar levels of outcome (Gresov and Drazin, 1997). Analytically, such multiple causal pathways require the test of conjunctural causation (Schneider et al., 2010), which can be achieved by configurational comparative methods such as fsQCA (Fiss, 2011; Ragin, 2008).

Culture shapes, and in turn is shaped by, institutions (Inglehart and Baker, 2000; Witt, 2008). In the literature, scholars subscribing to the crossvergence view emphasize the intricate connection between culture and institutions (e.g., Javidan et al., 2006; Redding, 2005; Witt, 2008; Witt and Redding, 2009) and suggest that the crux lies in the interactions between the two (Witt, 2008). In relation to national innovation performance, Taylor and Wilson (2012) conjecture that the effectiveness of different institutions (e.g., democracy, federalism, varieties of capitalism) in national innovation rates is conditional on different cultural values. We further argue that causal configuration equifinality allows for the possibility that multiple configurations of cultural and institutional dimensions can lead to the same level of national innovation performance. Fiss (2007) posits that a desired level of outcome can be achieved from different initial conditions and by a variety of different paths. In the context of national innovation, societies with distinct configurations of cultural and institutional varieties may adopt different national strategies to fulfill their aspiration to build an innovative society. Evidence has been found on the configuration of institutional varieties alone. Following the comparative institutional perspective (cf. Whitley, 1998, 1999), Hotho (2014) empirically confirms that several institutional configurations that include institutional varieties, such as union density, financial systems, state dominance and education systems, are conducive to innovation specialization in high-tech industries. For instance, it is found that high-tech innovation specialization can be promoted through a business system with deregulated labor markets and capital-based financing, but also facilitated by other business systems that feature little regulation, which can facilitate risk taking and knowledge dispersion through an equitable skill development systems (Hotho, 2014). We follow this approach to capture the possible 
equifinal configurations of cultural and institutional varieties that lead to national innovation performance, and we propose:

Proposition 2: There are equifinal configurations of cultural and institutional varieties that lead to an innovative society.

\subsection{Configuration with time effect}

Culture is commonly understood as enduring social patterns (Hofstede, 1980). Yet this does not mean that it never changes, although it would conceivably take an extended period for any change to become observable (Hofstede et al., 2010; Inglehart and Baker, 2000). Similarly, institutionalists have shown that institutions go through periods of marked change as well as stability (Seo and Creed, 2002). Based on the institutional change perspective, Dacin, Goodstein and Scott (2002: 47) argue that institutional change is influenced by "social pressures associated with differentiation of groups, the existence of heterogeneous divergent or discordant beliefs and practices, and changes in laws or social expectations that might hinder the continuation of a practice". The liberalizing initiatives of the European Union knocked down the barriers to trade and to the mobilization of employees, stimulating contemporary institutional changes (Hall and Thelen, 2009). It is argued that institutional changes are partly initiated by various agents of adjustment and particularly the government and firms in each country (Whitley, 2007). A prominent example of such endogenous institutional change is solidaristic wage bargaining in Sweden, where the movement toward centralized bargaining arrangements across export sectors unintendedly consolidated the bargaining position of unskilled workers, leaving less room for skilled labour (Pontusson and Swenson, 1996). The accumulation of firms" "deviant" behaviour in pursuit of new competitive strategies calls for the government to realign the regulatory rules accordingly (Hall and Thelen, 2009). On the 
other hand, institutional changes can also be triggered by a response to exogenous shocks (Whitley, 2007), like the recent Global Financial Crisis (GFC).

In a recent study examining the comparative institutions of 26 OECD countries, Schneider and Paunescu (2012) found that various institutional configurations that lead to a classification of LME and CME countries are not stable; for example, some commonly recognised CME countries, such as Denmark, Finland, the Netherlands and Sweden (cf., Hall and Soskice, 2001), all moved from the CME model to closer to the LME model between 1990 and 2005. This finding provides empirical evidence that institutional varieties are changeable and adjustable over a relatively short period, although such liberalising efforts as decentralizing collective bargaining, neutralizing unions, reducing employment protection and promoting equity investments do not occur together or necessarily result in radical transformation of the dominant institutions (Hall and Gingerich, 2009; Whitley, 2007). Even during a period when the formal institutional infrastructure appears to remain stable, the coordination of economic activities may still be altered by firms and workers through defects in institutionalised practices or reinterpretation of existing rules (Hall and Thelen, 2009). Rather than centralized efforts, institutional change is a process of mutual adjustment to distributive concerns by various actors in order to retain the comparative institutional advantage of the nation state (Hall and Thelen, 2009).

If both cultural dimensions and institutional elements can be altered proactively, the culture-institution mechanism may well be configurational. In other words, to achieve a strategic goal that the society desires (e.g., building an innovative society), the society can transform its cultural dimensions in the long run and institutional elements in the short run. For example, the increasing provision of "collective competition goods" such as highly trained workers and accessible capital by domestic agencies will help firms create organizational capabilities in relation to innovation (Crouch et al., 2001). These changes are particularly 
probable and tend to be significant when the endogenous forces from the dominant institutional regimes complement shifts in the international environment (Whitley, 2007). However, due to the institutional interaction, in that whether a change in one dimension of institutions can produce a desired outcome depends on the structure and complementarity of other institutional arrangements (Hall and Thelen, 2009), different countries may have motivations for mandating and endorsing different institutional reforms. This is manifest in the fact that, despite a society's ability to adjust institutional regimes over time, the move toward liberalization is not universal across OECD countries (Schneider and Paunescu, 2012). Thus, we posit our third proposition:

Proposition 3. If cultural and institutional varieties are configurational, a society can adjust or develop its cultural and/or institutional conditions to maintain or create its innovation leadership from time to time.

\section{Method}

\subsection{Research design}

This research explores the combinations of Hofstede's culture dimensions and the comparative institutional dimensions that exist among advanced economies to achieve high national innovation performance. Analytically, we follow a set-theoretic approach, utilizing the technique of fsQCA. Grounded in set theory, fsQCA is an analytic technique that allows for a detailed analysis of how causal conditions collectively contribute to an outcome in question (Crilly, 2011; Fiss, 2007, 2011; Misangyi et al., 2016; Ragin, 2008). The fsQCA technique is particularly suited for this study for three reasons. First, fsQCA enables the test of configurations as conjunctural causal effects, while traditional regression-based analysis is more suited for isolating an individual factor's effect, that is, so-called "general linear reality" or "net effects thinking" (Misangyi et al., 2016; 3; Ragin 2008). In so doing, traditional regression-based analysis has channeled efforts towards building and testing theories shaped 
by conceptions of "independent, additive, and symmetrical causality" (cf. Misangyi et al., 2016), which, in our study context, is evident in Shane's early efforts (e.g. 1992, 1993, 1995) in studying each individual Hofstede culture dimension influencing innovation. Given these different focuses, fsQCA is regarded as more analytically efficient than the regression approach in terms of detecting the collective influence of multiple causal conditions (Fiss, 2007; Ragin, 2008). Second, fsQCA models the concept of equifinality, following the principle that multiple combinations of causal conditions, rather than a single optimal solution, can lead to the desired outcome (Cui et al., 2017; Misangyi et al., 2016; Schneider et al., 2010). It thus has the advantage of capturing causal configuration equifinality, which allows for discovering different types of national innovation systems based on the nexus of cultural and institutional varieties. Third, fsQCA is suited for analysis based on a small-to-medium sized sample (Ragin, 2008), which is likely to be the case for studying country-level data with limited national varieties in scope and depth.

\subsection{Sample and data}

To explore the crossvergence perspective of cultural and institutional varieties, and assess the validity of configurations leading to a national innovation leadership, this study samples the 30 OECD member states for the 2010-2011 test and 25 OECD member states for the 20042005 test. The selection of OECD countries is for three reasons. First, developed market economies dominate in almost all key innovation indices and ranking systems. For example, by measuring patent applications worldwide, high-income and the upper middle-income countries (mainly OECD member states) occupy $60.3 \%$ and $36.4 \%$ of applications, respectively, in 2013, which also reflects their high R\&D spending (WIPO, 2014). Second, institutional varieties derived from the comparative institutional perspective are generally applied to developed market economies with relatively stable societal institutions (Hotho, 2014; Judge et al., 2014; Schneider et al., 2010). Third, culture dimension data are overall consistently 
available to OECD member states from the two major Hofstede culture value studies (his early stage one that was based on the IBM survey 1967-1973, and published in 1980; and his later work with reference to Minkov's World Values Survey in 2010). The sample includes countries that are frequently flagged in the innovation literature, such as the United Kingdom (UK), the US, Germany, Japan, South Korea, and the Nordic countries.

We selected 2005 and 2011 as our focal years for innovation performance, and 2004 and 2010 for measuring causal conditions. We used the most recent data available before either 2004-2005 or 2010-2011 if data for the two time periods were not yet available. The outcome variable was sourced from the 2005/2011 patent data in the OECD/EPO patent database. The culture dimension data were sourced from Hofstede, Hofstede and Minkov (2010) for the 20102011 test, while data presented in Hofstede (1980) were used for the 2004-2005 test, because these not only have construct measurement validity but are also regarded as the latest available data source for Hofstede's culture indicators. Hofstede et al. (2010) argued that the culture dimension will not change frequently over decades.

The institutional indicators were measured from diversified data sources. The data source for Union Density is the ICTWSS database 4.0, which was compiled and measured by Visser (2013). Measuring the Strength of Education System is controversial in the literature. Researchers (e.g., Schneider et al., 2010; Zhang and Yang, 2006) have adopted two measures of the training system, namely, university training and occupational training, and conclude that LME countries are characterized by a high extent of university training, while CME countries feature a high degree of occupational training. The conclusion is ideological and debatable, because the quality of either university- or occupational-training institutions across countries is not able to be compared. For this reason, this study embraces the measurement adopted by Hotho (2014), who argued that strong education systems should overcome student social backgrounds and ensure an equitable distribution of learning opportunities and development 
outcomes (cf., OECD, 2010). Therefore, in such a system, student performance is less affected by variation between schools than less-effective education systems. Therefore, this study adopts data collected from the OECD programme for International Student Assessment (PISA) database 2000 and 2009, because the PISA results generally predict the quality of a labour force one decade later in the country according to OECD longitudinal studies (cf., OECD, 2014). The ratio of Market Capitalization to Credit was calculated from two data sources, namely, data on market capitalization obtained from the World Bank World Development Indicators and the Global Development Finance database 2004/2011. Data on private credit by deposit money banks were obtained from the World Bank Financial Structure dataset 2004/2013. In this sense, scores above 1 indicate that the financial systems are more based on the capital market, while scores less than 1 reflect financial systems relying on credit. Pervasiveness of Clusters and the intermediary associations indicator was adopted from the Global Competitiveness Report (WEF, 2004, 2010), which measures how prevalent welldeveloped and deep clusters (including research institutes and training providers) are in each country's economy. The main data source for measuring State Dominance is also the Global Competitiveness Report (WEF, 2004, 2011), which has been a widely used source of institutional data (e.g., Hotho, 2014; Rao et al., 2005).

Insert Table 1 about here

\subsection{Calibration}

Outcome: The primary outcome of interest in our study is revealed in innovation specialization (RIS). The RIS index as used here reflects the share of patenting of a country in a sector relative to its share of patenting in all industries, and is a frequent measure of innovation specialization (e.g., Dunning, 1994; Hall and Soskice, 2001; Hotho, 2014; Vertova, 2001). Following Hotho (2014), the Balassa index of RIS in biotechnology, nanotechnology, 
and information and communication technology uses patent data from the OECD/EPO patent database. We selected these sectors because they depend heavily on research outputs from OECD countries, in which cultural mechanisms and institutional varieties are often claimed to have either cultural or institutional comparative advantage (Hall and Soskice, 2001; Shane, 1992, 1993). The literature (e.g., Dunning, 1994; Hall and Soskice, 2001) suggests that innovation activities rather than the value of innovations can reflect well on the national innovation flagship; we, therefore, adopt patent counts rather than forward citations. The equation of the RIS index is as follows:

$$
R I S_{i j}=\frac{\frac{P_{i j}}{\sum_{i} P_{i j}}}{\frac{\sum_{j} P_{i j}}{\sum_{i} \sum_{j} P_{i j}}}
$$

The nominator reflects EPO patent applications $(\mathrm{P})$ from country $\mathrm{j}$ in sector $\mathrm{i}$ as a proportion of total EPO patent applications from country $\mathrm{j}$. The denominator reflects the total number of EPO patent applications in sector $i$ as a share of the total number of patent applications from the sample of OECD countries. An RIS value of more than 1 signifies that a country is relatively specialized in innovation in sector i. For the purpose of this study, we calculated a combined RIS country score for the biotechnology, nanotechnology and ICT sectors for both 2005 and 2011.

In our research, the fuzzy-set measurement of RIS was based on Fiss's (2011) calibration rules. Specifically, for the RIS in 2011, countries with RIS index above 1.04, such as the US and Canada, were considered full members (i.e., a score of 1 ) in the set. Scores between 0.82 and 1.04, including the UK and Australia, were considered to have a high degree of membership at the 0.67 level. Scores between 0.59 and 0.82 received 0.33 , which includes countries like Denmark and Greece. Countries with scores below 0.59, such as Italy and Norway, were coded as full non-membership (i.e., a score of 0 ) of the set. 
Culture Indicators: Based on raw data about national cultural dimensions, we assigned group membership to each country in each causal condition following Ragin's (2008) technique: full membership (1), full non-membership (0), and the crossover point (0.5). Since all of our culture indicators are adopted from Hofstede's national cultural dimensions, and they share the same scale of measurement in 2004 and 2010, we can use one fuzzy-set method to calibrate all of our culture indicators in both years. Specifically, for any of our four cultural indicators, countries with score below 5 were calibrated as fully out of the set $(0)$, while countries with score above 95 were assigned as fully in the set of a high degree of a certain cultural dimension (1). As a crossover point, we chose a score of 50 for each national cultural dimension, which is consistent with prior studies' calibration approach (Fiss, 2011; Judge et al., 2014).

Institutional Indicators: For the calibration of institutional indicators in our study, we followed Hotho's (2014) method for the fuzzy-set measure of institutional causal conditions in both 2004 and 2010. To transform institutional variables into fuzzy-set membership scores, firstly we specified three qualitative anchors for each institutional indicator (Ragin, 2008): full membership, full non-membership, and the crossover point at which cases are neither fully in nor fully out of a given set. In line with recommendations from fuzzy-set method scholars (Ragin, 2008; Schneider and Wagemann, 2010), the qualitative anchors are theoretically informed where possible. Where theoretical knowledge offers less guidance on cut-off points, such as with variables from the World Bank Financial Structure Dataset, we set anchors through substantive case knowledge (Schneider and Wagemann, 2010). As Ragin (2008) commented, cases with membership scores of exactly 0.5 are difficult to analyse. Thus we followed Hotho's (2014) and Fiss's (2011) calibration methods for institutional causal conditions and deducted 0.05 from the identified crossover points of variables on interval scales. For example, the crossover point of State Dominance in 2010 was set at 2.4, and it was then 
redefined as 2.35. In this study, we calibrated the 2004 and 2010 institutional indicators separately, because the scales in our data sources (such as the Global Competitiveness Report) are sometimes equivalent but not identical across editions. Then we assigned membership scores with the calibration function in the fsQCA 2.5 software, which applies the log odds method described in Ragin (2008). This produced a fine-grained calibration of the degree of set membership of cases, with scores ranging from 0.00 to 1.00 . The detailed anchor points used for calibrating institutional indicators were reported in Table 1.

\section{Results}

We started the analysis by testing whether any of the causal conditions qualified as a necessary condition for RIS. The purpose of this step is to identify the presence of any potential necessary conditions to be signaled in the subsequent analysis of configurational solutions. In fsQCA, a condition is considered "necessary" or "almost always necessary" if the condition is required but not necessarily sufficient for an outcome to occur (Schneider et al., 2010; Ragin, 2008a). As shown in Table 2, we tested whether any of the nine causal conditions was necessary to account for national innovation leadership. The results suggested that none of the individual conditions exceeded the consistency threshold of 0.90 for a necessary condition (Schneider et al., 2010). Therefore, no necessary condition was to be signaled in the subsequent analysis.

Insert Table 2 about here

Table 3 shows the results of fuzzy-set analysis of the causal effect of configurations of both cultural and institutional varieties on national innovation leadership. The configurational solutions are presented in the style the follows the recommendation of Ragin and Fiss (2008), which has been widely adopted in the literature (see Crilly, 2011; Fiss, 2011; Hotho, 2014; Ragin, 2008). With regard to the notation, black circles $(\bullet)$ indicate the presence of a condition and a circled cross $(\otimes)$ indicate its absence. Blank spaces indicate ambiguous situations, in 
which the corresponding causal condition may be either present or absent, and therefore they play no significant role in the configurational solution. Following Greckhamer (2011) and Ragin (2008), the intermediate solutions generated by fsQCA2.5 were reported, because the intermediate solutions are more conservative with stronger empirical plausibility (cf. Ragin, 2008). In so doing, there are no distinctions between large circles that indicate core conditions and small ones as peripheral conditions, which are derived from parsimonious solutions and adopted by some studies for serving taxonomy development (e.g., Fiss, 2011; Hotho, 2014).

Insert Table 3 about here

Two measures of model fits, namely, consistency and coverage, were reported in Table 3. The consistency score measures how well the solution corresponds to the data (Crilly, 2011; Ragin, 2008). The score is calculated for each configuration separately, and for the whole solution. The measure of consistency can range from 0 to 1 (Ragin, 2008a), with a high value indicating greater consistency between the theoretical relationship and the actual data. Existing studies have adopted various standards for a consistency threshold. For example, several studies suggest an acceptable consistency level of 0.80 (Crilly, 2011; Fiss, 2011; Misangyi and Acharya, 2014), while Schneider et al. (2010) chose a threshold level of 0.90, and a gap was observed in the distribution of consistency scores. Following the latter approach, we applied a threshold of 0.955 for the 2011 RIS test and a threshold of 0.986 for the 2005 RIS test.

The second fit indicator measures solution coverage. We obtained a coverage of 0.41 with solutions for the 2011 RIS test and a coverage of 0.52 for the 2005 RIS test. These overall coverage levels indicate the empirical importance of our solutions as a whole (Crilly, 2011; Ragin, 2008). Table 3 also reports the raw coverage and unique coverage levels for each individual configurational solution. The raw coverage measures the explanatory power of an individual configurational solution. However, any single observation might be explained by 
multiple configurations, and therefore a measure of each configuration's unique contribution to RIS is provided in the form of unique coverage.

Based on the Quine-McCluskey algorithm (the method of prime implicants) that gives a deterministic way to verify that the minimal form of a Boolean function has been reached, the solution table (Table 3) shows that both the 2010-2011 test and the 2004-2005 test generate seven configurations. We classified all configurations into three groups, which are mainly grounded by the presence of representative case countries. The representative cases were derived from a counterfactual analysis to speculate about the most theoretically plausible outcomes of the combinations that do not exist in the data set (Crilly, 2011, Fiss, 2011; Ragin, 2008). Causal combinations of conditions exceeding an appropriate cut-off consistency score were categorized as sufficient, and the outcome was therefore assigned a value of 1. Conversely, causal combinations with a consistency level below or at the cut-off value were not considered sufficient, and the outcome was assigned a value of 0 . Setting a frequency threshold of one observation is usually advised for a relatively small sample (cf. Crilly, 2011; Ragin, 2008), and this is also an operational strategy (cf. Crilly, 2011; Hotho, 2014; Judge et al., 2014) for dealing with the limited diversity of combinations (that is, the logically possible causal combination $2^{\mathrm{k}}$ possibilities, such as $2^{9}$ in this study, exceeds the sample size). Cases with set membership great than 0.5 were selected. Group I includes countries, such as Sweden (solutions Ia \& Ih) and Australia (solutions Ib \& Ii), which show exactly the same results between the two time period tests. Group II contains three countries, namely, the UK (IIc \& IIj), Finland (IId \& IIk) and Ireland (IIe \& IIl). Under this group of countries, the three countries retain their national innovation leadership among all OECD countries, but their institutional varieties have changed in order to maintain innovation competitiveness. Group III represents countries whose national innovation configurations have either emerged, such as the Spain model (solution IIIf) and the 
US model (solution IIIg), or declined, including the Netherlands model (solution IIIm) and the Japan model (solution IIIn). Configurations are detailed as follows.

\subsection{Group I: Innovative societies with time robustness}

Solutions Ia and Ih represent the Swedish innovative model. In this model, the society is highly individualistic, and has uncertainty tolerance, non-masculinity, and low power distance in its culture gene. Although the country does not have comparatively strong education system, nor does it have the state dominance effect, Sweden has high union density, a capital-marketbased financial system and the prevalence of clusters. The finding is consistent with some previous studies: for example, Hotho (2014) also showed low direct state involvement and saw informal coordination and negotiation among special interest groups. Amable (2003) stated that Sweden is a typical social-democratic country, while Boyer's (2004) classified Sweden as a knowledge-based economy.

Solutions Ib and Ii reflect Australian society with combined features of a geographically isolated democratic economy and an Anglo-Saxon dominated social culture. In its culture, Australian society generally prefers uncertainty avoidance, is male-dominated, and is individualistic but has low power distance. In its institutions, the country has comparatively strong skill training and development systems and an effective capital-market-based financial system with low union density, low state dominance and the absence of cluster prevalence. The findings support country highlights presented by the Global Competitiveness Report that Australia has strong financial market development with public institution excellence, and retains its training and education strength, but the labor market is a concern (WEF, 2011, 2014).

\subsection{Group II: Innovative societies with institutional change}

Solutions IIc and IIj reflect the UK innovative model. In the UK, society accepts uncertainty and risk arising from the future unknown aspect, and prefers low power distance, 
but the society is also a masculinity- and individualism-dominated one. The UK has high union density, a strong education system, and prevalent industrial clusters, but its financial system remains comparatively reliant on a bank-based credit mechanism, that is, its capital-marketbased system remains relatively weak. State dominance reflects the institutional work conducted by the country. Solution IIj shows the configuration does not depend on the element of state involvement in 2004-2005, while solution IIc emphasizes an absence of state dominance as a causal condition. This is consistent with the institutional structuring literature, in which anti-trust regulations and competition policies are considered a major endogenous change commonly found in arm's-length economies (Whitley, 2007). For instance, David Cameron's coalition government (from 2010 to 2016) continued some of the economic policies from Tony Blair Labour government (1997-2005), such as supporting the National Minimum Wage Act 1998 introduced by the Labour Party, but the Cameron government more firmly supported free trade and an open economy, which was evident in less state intervention in the economy, such as the deregulation of the private sector, and a reduction in corporate tax to $25 \%$ and to $20 \%$ for small businesses.

Solutions IId and IIk illustrate the Finnish model. Finnish society prefers to avoid uncertainty but promotes individualism. Also, the society is in favor of gender equality and non-power distance. The country has consistent high union density, strong prevalence of clusters and less state dominance. For maintaining its national innovation leadership, the country has adjusted its institutions, such as the skill training system and financial system (cf., solutions IId and IIk). Overall, compared with national educational systems internationally, and notwithstanding the Finnish education system has a consistently high ranking, its PISA ranking has been displaced from the top in recent years (OECD, 2010). Moreover, according to the IMF (2010), there has been a significant increase in the range of deposit-taking institutions (commercial, cooperative and savings banks), which stand at the core of Finland's 
financial system; and total banking assets were around EUR 350 billion at end-2009 (equivalent to about $200 \%$ of GDP), up from 110 percent of GDP in 2003. The results of the GFC resulted in large dislocations of financial flows in Finland (i.e., occupying $70 \%$ of all banking system assets), and, as a consequence, the Finish "domestic corporate debt issue fell sharply in 2008 and was to a large extent replaced by bank credit" (IMF, 2010: 9). This change reduces Finnish companies' financial risk, and to some extent boosts their risk tolerance (or complements their uncertainty avoidance as national culture insufficiency for innovation) in innovation activities at corporate level.

Solutions IIe and IIl reflect the national innovative model of Ireland. Similar to the cultural characteristics of the UK model (e,g., IIc and IIj), Irish society prefers uncertainty acceptance, masculinity and low power distance with independence and individualistic spirit. The Irish business culture has been recommended as a "sophisticated and innovative" one (WEF, 2011: 24). Supporting Hotho's (2014) findings, Ireland has demonstrated consistently high union density and strong foundation-level education system in building an innovative society. In contrast to Hotho (2014), it is found that the presence of state dominance is one of the key characteristics of Irish innovative style. The Irish government continued to increase its public expenditure and funded expensive capital projects even after the collapse in property-related tax revenue that caused the fiscal crisis in Ireland in 2006-2008 (EU, 2012). The institutions of society have also changed from 2004-2005 to 2010-2011. The Irish national innovative system does not rely on a capital market-based financial system, which is a factor weakening national competitiveness (WEF, 2011). Due to the bursting of the Irish property bubble, the post-2008 Irish banking crisis and the GFC, the country has significantly reformed its banking sector, such as deleveraging of bank balance sheets, completing bank mergers and enhancing corporate governance (EU, 2012). Another explicit change is related to prevalence of clusters, which appeared to be a solid contributor in 2004-2005, but the absence of that element is important 
in 2010-2011. It is evident that the government has reformed sectoral labor market agreements, and made on-going efforts to encourage more competition in "sheltered" clusters, such as the legal professions, thus bringing down costs and stimulating a competitive economy (EU, 2012).

\subsection{Group III: Innovative societies with transformational features}

Solutions IIIf and IIIg represent two "emerging" innovative societies during the test window period, Spain and the US, respectively. Spanish society culture is characterized by uncertainty avoidance, individualism, gender equality and high power distance. In its institutional features, the country emphasizes education, shown in the large proportion of the population that pursues higher education (WEF, 2014), and state involvement in economic policies, such as a notable effort towards public investment in infrastructure (WEF, 2011). Nevertheless, the absence of union density, a capital market based financial system and cluster prevalence are important contributors. The innovativeness of the Spanish society is echoed in Hotho's (2014) findings. The emergence of the Spanish model reflects the extensive economic restructuring, knowledge adoption and liberalization processes in the 1990s (Hotho, 2014; WEF, 2011).

The US has dominated in a number of radical innovation events (e.g., personal computers, biotechnology, and the internet) since World War II. However, our fsQCA analysis, a counterfactual analysis in particular, does not highlight the country in the 2004-2005 test compared with other countries, but does show the society in the 2010-2011 test. We therefore classified the American society as an "emerging one". This emergence can be understood as a lack of macroeconomic stability that continues to be the US' "greatest area of weakness" (cf. WEF, 2011: 23; WEF, 2014). The society features in risk taking, masculinity, individualism and low power distance in its culture, and low union density (e.g., "the ease and affordability of hiring workers and significant wage flexibility" (WEF, 2011: 14)); it is comparatively weak 
in its equity-orientated skill development system (that is, on the contrary it promotes an "elite" education system), a strong capital-market-based financial system, and strong state dominance in the economy in its institutions.

Solutions IIIm and IIIn indicate two countries, the Netherlands and Japan, in the 2004-2005 test, but they did not appear again in the 2010-2011 test. We therefore term the two national innovation configurations as "transient" ones. Dutch society features uncertainty avoidance, gender equality, individualism and low power distance in its culture, while Japanese society is embedded in a culture of uncertainty avoidance, masculinity, collectivism and high power distance. Among the five institutional indicators, both the Netherlands and Japan models demonstrate only one element (i.e., skill development for the Netherlands and prevalence of clusters for Japan) as a key contributor, and all the other four indicators remain absent. By contrast, all the other five solutions, either in 2004-2005 or in 2010-2011, show at least two institutional elements as key contributors. This sole presence type of instructional structure might support the two countries in maintaining national innovative competitiveness during global economic boom periods (e.g., 2000-2005), but cannot survive or work efficiently in a turbulent economic and social environment, such as the GFC.

In summary, the resultant configurational solutions shown in Table 3 support our propositions. Overall, the consistency scores demonstrate the presence of a clear set-theoretic relationship. In other words, there is a clear nexus of cultural and institutional varieties working in configurations, rather than in isolation, to enable RIS. A closer look at the configurational solutions suggests that all solutions involve at least one causal condition from either Hofstede's four culture dimensions or comparative institutional indicators. Therefore, we find support for the proposition that the collective influence of cultural and institutional varieties explains OECD countries' efforts in building an innovative society. Proposition 1 is supported. Moreover, we find multiple configurational solutions for achieving high RIS performance. This 
indicates that an innovative society can be achieved by multiple cultural and institutional configurations. The presence of the three overall groups of solutions thus points to a situation of across-type, equifinality of solutions (e.g., Fiss, 2011). Proposition 2 is supported. Further, building upon Shane $(1992,1993,1995)$ and Furman et al. (2002), our findings suggest that there is no one best way to configure an innovative society, and a high RIS performance can be secured by relying on its culture roots, adjusting and developing its institutional varieties. For example, Group II solutions indicate that countries can proactively or passively change their institutions in order to maintain their innovative flagship, although their culture varieties cannot be changed in the short run, while Group III solutions demonstrate that countries with certain culture-institutional configurations might not be able to consistently protect their national innovation competitiveness. Such dynamism confirms our Proposition 3.

\section{Discussion}

\subsection{Implications for the theory}

Scientific research has generated numerous insights as to why any individual or organization is more innovative than others, yet the lasting puzzle - why some societies enjoy comparative advantages in high-tech sectors - has not been fully addressed, and remains an important topic for social scientists. Our study addresses this question, and provides some important theoretical implications.

First, compared with culturists' efforts (e.g., Shane, 1993, 1995), our findings show that the other two key culture dimensions, namely, uncertainty avoidance vs. acceptance, and masculinity vs. femineity, are contributing factors in several configurations (e.g., solutions Ib, IIIn), but not in others (e.g., solution Ia). This finding resolves some debates on the inclusion of these culture dimensions for anticipating an innovative society in the literature. For example, scholars (cf. Rinne et al., 2012; Shane, 1993, 1995) hold different opinions as to whether 
uncertainty acceptance is necessary for being an innovative nation. Based on the configurational approach and a set-logic, our finding suggests that all these culture indicators are contributory and configurational, but not in a linear fashion assumed by previous regression analyses.

Second, in addition to the comparative institutional thinking, this study adds cultural dimensions to account for national innovation performance. The resulting representative case countries identified are largely consistent with Hotho (2014). For example, case countries in our study, such as Sweden, Australia, the UK, Finland, Ireland and the US, are also high-level national innovation representative countries in the study by Hotho (2014). Hotho (2014: 21) promotes the Nordic business system, which features "low direct state involvement, high trust, a strong public training system and considerable cooperation and coordination across actors". Our findings also demonstrate that two of seven solutions in the two rounds of tests are from the Nordic countries, Sweden and Finland. However, given the configurational equifinality (Fiss, 2007, 2011; Gresov and Drazin, 1997), we argue that, when countries face multiple and sometimes conflicting cultural and institutional varieties which require prioritizing to obtain an achievable outcome level (i.e., national innovation performance), countries differ in their functional prioritization, which leads to different configurations that may generate the same or similar levels of outcome. Therefore, our study seeks to downplay the superiority of the Nordic business system claimed by Hotho (2014); rather it contends that the Nordic business system (i.e., the Swedish and Finish configurations in this study) is just one of the alternative paths that produces, reproduces and transforms national innovation outcomes. Based on the equifinality and our empirical findings, it is evident that the Anglo-Saxon model (such as the UK, Ireland, Australia and the US) is also equally effective in leading to building an innovative society. 
Third, the comparative institutional perspective argues for sector-specific comparative advantages. For example, CMEs might be good at incremental innovation, while LME countries are strong in radical innovation (Hall and Soskice, 2001; Hall and Gingerich, 2009); likewise, CMEs export more heavily in medium high-tech industries and LMEs in high-tech industries (Schneider et al., 2010; Cui et al., 2016). All these findings are based on a static view of comparative institutional perspective. Our Group III countries, such as the presence of Spain and the US in 2010-2011, the presence of the Netherlands and Japan in 2004-2005, and the disappearance of these countries in another round of tests, clearly indicate that institutional varieties are not enduring social patterns. Similar to Schneider and Paunescu (2012), our findings also show mixed evidence for the comparative institutional claims made by Hall and Soskice (2001). Based on our findings, we argue that the theoretical development of comparative institutional perspective should enhance its theoretical explanation power for institutional dynamism.

\subsection{Implications for policymakers}

This study uses a fuzzy-set approach to explore the combinations of Hofstede's culture dimensions and the comparative institutional varieties that enable some OECD countries to achieve higher national innovation performance than others. This study contributes to both international business and innovation policy by providing three key findings. First, we confirm that culture and institutions co-evolve and affect each other in a path-dependent way. Institutions need to be complemented by culture to be able to increase innovation and vice versa. Second, we show that the end result of the evolutionary process is a distinct configuration of culture and institutions for each society. Some configurations are better suited for producing innovative activities in high-tech sectors than others. This suggests that combinations of culture and institutions follow a set logic rather than the conditional effectiveness implied by Taylor and Wilson (2012). Third, we show that the configurations do 
change as the evolutionary process proceeds, stimulated by external shock. When a causal condition is absent, the country may no longer be able to maintain its comparative advantage in innovation as before. We suggest that societies can adjust or develop their cultural and/or institutional conditions to maintain or create their innovation leadership.

\subsection{Implications for practices}

In addition to the solutions detailed in the last section, there are several findings worth mentioning. First, among all 14 configurations, 13 contain the presence of individualism and the absence of power distance as key contributors to being innovative societies; the only two exceptions are the Spanish model in 2010-2011 (solution IIIf) with power distance and the Japanese model (solution IIIn) in 2004-2005 with collectivism. The consistency of findings largely supports Shane's (1992) arguments, that is, a society that stresses social hierarchy discourages innovative activities, while individualistic societies are more innovative than collectivistic ones. For example, in individualist societies, the purpose of getting an education is to learn how to learn, while the purpose of education in collectivist societies is to learn how to do (Hofstede et al., 2010; Rinne et al., 2012). According to Rinne et al. (2012), in a world in which technology is rapidly changing, individualistic societies that emphasise learning how to learn may put such nations in a better position, because members are constantly needing new skills, and this in turn fosters innovation. Unsurprisingly, the appearance of collectivism in the Japan model (solution IIIn) also supports findings from Taylor and Wilson (2012), that is, collectivism in certain situations may actually foster national innovation rates.

Further, the seven solutions derived from both the 2010-2011 test and the 2004-2005 test also appear relatively robust over time, which confirms some findings from Hotho (2014). The robustness mainly reflects culture dimension consistency in terms of measurement and being severed as complementary conditions, and the overall representative case countries of Group I 
and II solutions. Group I countries, such as Sweden and Australia, show their own identical solutions over time. This is consistent with Whitley's (2007) proposition that strong and complementary governance relations among domestic actors can withstand external shocks and remain effective in providing the institutional resources required for innovation. Although Group II countries, such as the UK, Finland and Ireland, maintain their national innovation leadership, the fsQCA analysis captures the relative changes in their institutional characteristics. The finding provides empirical evidence to the institutional change theory, which, at a more macro level, argues that efforts are influenced by social movements and entail the fundamental realignment of a significant number of participants' frames and logics of action (Seo and Creed, 2002). In this context, institutional change happens when the weakening and disappearance of one set of beliefs and practices is associated with the arrival of new beliefs and practices (Dacin et al., 2002). The fact that some countries need to adjust their institutional arrangements to sustain their competitive position while others do not suggests that the consequences of exogenous environmental changes are not universal and may depend on the complementarity of extant institutions (Whitley, 2007). Those countries with less cohesive associations among interest groups, like employers and labour organizations, may have to adapt to the new environment in order to consolidate the value of the domestically provided "collective competition goods" and thus maintain an internationally competitive position.

\subsection{Limitations and future research}

Some limitations of the study need to be acknowledged, but these nevertheless indicate potential directions for future research. First, the "limited diversity" issue - an intrinsic limitation of the fuzzy set methods (Crilly et al., 2012; Ragin, 2008) - is a potential threat to internal validity of our research. Unlike regression-based analyses, control variables cannot be included in fsQCA in a conventional sense, and the total number of causal conditions is limited by the sample size. We follow Ragin (2008) in deriving causal conditions from existing theories, 
and only select high-order, i.e., the most important, ones. Specifically, we set a frequency threshold of one observation in our truth table analysis. Although our choice of causal conditions leads to parsimonious theory building, it could cause potential threats of "limited diversity" insufficiency. Therefore we call for future studies to include more causal conditions wherever possible and further test the validity of our findings.

Second, our focus on national innovation among advanced economies (e.g., OECD member countries) may pose a threat to external validity. As mentioned in the methods section, although we study the whole "population" of OECD countries, rather than a randomly selected "sample", the data source availability across years limits the total number of countries included. Therefore, the sample size cannot generate sufficient empirical cases (29) to cover theoretical possibilities. Given this limitation, future study can either conduct analyses on alternative causal conditions by using different theoretical lenses as an extension to the current study for national innovation research, or repeat our research design in a sample of developing countries. In so doing, the generalizability of the findings might be enhanced, and both approaches call for new theory building other than comparative capitalism.

Third, this study is limited to exploring country-level innovation performance. We have identified several countries with national innovation excellence. The managerial implication of the findings is that these countries might be the best locations for research and development for multinational corporations and even the entire human society (cf. Shane, 1992). We also agree with scholars (e.g., Jackson and Deeg, 2008; Schneider et al., 2010) who argue for the relation between country-level competitiveness and organizations' institutional arbitrage. We further add the possibility of the cultural arbitrage concept for firm-level studies, because culture is configurational and leads to culture competitive advantages (cf. Shane, 1992, 1993). The identification of national innovation excellence among advanced economies may be 
explored by using the (institutional/culture) arbitrage perspective to connect with organizational-level research in the future.

\section{Conclusion}

This study explores configurational solutions leading to higher national innovation performance among OECD member countries in the high-technology sectors. Embraced with a crossvergence perspective, the study involves four cultural dimension based and five institution related causal conditions and investigates the three propositions with two rounds of data. Our results identify three groups of highly innovative societies, namely, Australia and Sweden as innovative countries with time robustness; the UK, Finland and Ireland changing some institutional settings to maintain as innovative societies; Spain, the US, Netherlands and Japan as being innovative societies once at certain time points due to transformational features. The study confirms the equal importance of both cultural and institutional mechanisms as contributors to national cutting edge innovation, and identifies equifinal configurations of cultural and institutional varieties as leading to a high-tech society. In addition, if cultural and institutional varieties are configurational, a society can adjust or develop cultural and/or institutional conditions to maintain or create leadership in innovation.

There are a number of practical and theoretical implications of this study, as discussed in the discussion section above. In particular, this study emphasizes on the configurational thinking of creating /disrupting and maintaining innovative societies. Moreover, from a crossvergence perspective, the study pioneers in bringing both culture and institutional varieties to study national innovation systems, rather than just focus on the impact of either cultural dimensions or political and economic institutions on national innovation performance. Given some limitations, such as, only sampling advanced economies, we urge the need for 
further research to explore the crossvergence perspective of cultural and institutional varieties and their impact on national innovation performance in developing economies. 


\section{References}

Acharya, V.V., Baghai, R.P., Subramanian, K.V., 2014. Wrongful discharge laws and innovation. Review of Financial Studies, 27 (1), 301-346.

Akkermans, D., Castaldi, C., Los, B., 2009. Do 'liberal market economies' really innovate more radically than 'coordinated market economies'? Hall and Soskice reconsidered. Research Policy, 38 (1), 181-191.

Allen, M.M.C., 2012. Comparative capitalisms and the institutional embeddedness of innovative capabilities. Socio-Economic Review, 11 (4), 771-794.

Amable, B., 2003. The diversity of modern capitalism. Oxford, UK: Oxford University Press.

Bessant, J., Grunt, M., 1985. Management and Manufacturing Innovation in the United Kingdom and West Germany. Aldershot, UK: Gower Publishing Company.

Cantwell, J., Dunning, J.H., Lundan, S.M., 2010. An evolutionary approach to understanding international business activity: the co-evolution of MNEs and the institutional environment. Journal of International Business Studies, 41 (4), 567-586.

Carlsson, B., 2006. Internationalization of innovation systems: a survey of the literature. Research Policy, 35 (1), 56-67.

Chui, A.C.W., Lloyd, A.E., Kwok, C.C.Y., 2002. The determination of capital structure: is national culture a missing piece to the puzzle? Journal of International Business Studies, $33(1), 99-127$.

Clausen, T.H., 2014. The role of institutional arbitrage in the search for product innovation: firm level evidence from Norway. Industrial Marketing Management, 43 (3), 392-399.

Crilly, D., 2011. Predicting stakeholder orientation in the multinational enterprise: a mid-range theory. Journal of International Business Studies, 42 (5), 694-717.

Crilly, D., Zollo, M., Hansen. M., 2012. Faking it or muddling through? Understanding decoupling in response to stakeholder pressures. Academy of Management Journal, 55 (6), 1429-1448.

Crouch, C., Le Galès, P., Trigilia, C., Voelzkow, H., 2001. Local Production Systems in Europe: Rise or Demise? Oxford: Oxford University Press.

Cui, L., Fan, D., Liu, X., Li, Y., 2017. Where to seek strategic assets for competitive catch-up? A configurational study of emerging multinational enterprises expanding into foreign strategic factor markets. Organization Studies, forthcoming. DOI: $10.1177 / 0170840616670441$. 
Dacin, M. T., Goodstein, J., Scott, W. R., 2002. Institutional theory and institutional change: introduction to the special research forum. Academy of Management Journal, 45 (1), 4356.

Dunning, J. H., 1994. Multinational enterprises and the globalization of innovatory capacity. Research Policy, 23 (1), 67-88.

Efrat, K., 2014. The direct and indirect impact of culture on innovation. Technovation, 34 (1), 12-20.

EU (European Commission). 2012. Ireland's economic crisis: how did it happen and what is being done about it? Retrieved from http://ec.europa.eu/ireland/key-eu-policyareas/economy/irelands-economic-crisis/index_en.htm. Accessed on [10-Dec-2014].

Fiss, P.C., 2007. A set-theoretic approach to organisational configurations. Academy of Management Review, 32 (4), 1180-1198.

Fiss, P.C., 2011. Building better causal theories: a fuzzy set approach to typologies in organisation research. Academy of Management Journal, 54 (2), 393-420.

Freeman, C., 1995. The national system of innovation in historical perspective. Cambridge Journal of Economics, 19 (1), 5-24.

Furman, J.L., Porter, M.E., Stern, S., 2002. The determinants of national innovative capacity. Research Policy, 31 (6), 899-933.

Greckhamer, T., 2011. Cross-cultural differences in compensation level and inequality across occupations: a set-theoretic analysis. Organization Studies, 32 (1), 85-115.

Gresov, C., Drazin, R., 1997. Equifinality: functional equivalence in organization design. Academy of Management Review, 22 (2), 403-428.

Hall, P., Gingerich, D., 2009. Varieties of capitalism and institutional complementarities in the political economy: an empirical analysis. British Journal of Political Science, 39 (3), 449482.

Hall, P., Soskice, D., 2001. An Introduction to Varieties of Capitalism'. In: P. Hall and D. Soskice (eds.) Varieties of Capitalism: The Institutional Foundations of Comparative Advantage. Oxford: Oxford University Press.

Hall, P.A., Thelen, K., 2009. Institutional change in varieties of capitalism. Socio-Economic Review, 7 (1), 7-34.

Herrera, L., Nieto, M., 2008. The national innovation policy effect according to firm location. Technovation, 28 (28), 540-550.

Hofstede, G., 2006. What did GLOBE really measure? Researchers' minds vs respondents' minds. Journal of International Business Studies, 37 (6), 915-921. 
Hofstede, G., 2011. Dimensionalizing Cultures: The Hofstede Model in Context. Online Readings in Psychology and Culture, 2 (1). http://dx.doi.org/10.9707/2307-0919.1014

Hofstede G., Neuijen B., Ohayv D. D., Sanders G., 1990. Measuring organizational cultures: a qualitative and quantitative study across twenty cases. Administrative Science Quarterly, 35, 286-316.

Holmes, R.M, Miller, T., Hitt, M.A., Salmador, M.P., 2013. The interrelationships among informal institutions, formal institutions, and inward foreign direct investment. Journal of Management, 39, 531-566.

Hotho, J.J., 2014. From typology to taxonomy: a configurational analysis of national business systems and their explanatory power. Organization Studies, 35 (5), 671-702.

Inglehart, R., Baker, W.E., 2000. Modernization, cultural change, and the persistence of traditional values. American Sociological Review, 65 (1), 19-51.

Jackson, G., Deeg, R., 2008. Comparing capitalisms: understanding institutional diversity and its implications for international business. Journal of International Business Studies, 39 (4), 540-561.

Javidan, M., House, R.J., Dorfman, P.W., Hanges, P.J., de Luque, M.S., 2006. Conceptualizing and measuring cultures and their consequences: a comparative review of GLOBE's and Hofstede's approaches. Journal of International Business Studies, 37 (6), 897-914.

Judge, W.Q., Fainshmidt, S., Brown III, J.L., 2014. Which model of capitalism best delivers both wealth and equality? Journal of International Business Studies, 45 (3), 363-386.

Krugman, P., 1991. Geography and Trade. Cambridge, MA: MIT Press.

Landes, D., 2000. Culture Makes Almost All the Difference. In L.E. Harrison and S.P. Huntington (eds.) Culture Matters: How Values Shape Human Progress: p.2-13. New York: Basic Books.

Landes, M., 1970. The Unbound Prometheus: Technological and Industrial Development in Western Europe from 1750 to the Present. Cambridge, Cambridge University Press

Lundvall, B.A., 2007. National innovation systems: analytical concept and development tool. Industry and Innovation, 14 (1), 95-119.

Manso, G., 2011. Motivating innovation. Journal of Finance, 66 (5), 1823-60.

Merritt, A., 2000. Culture in the cockpit: do Hofstede's dimensions replicate? Journal of Crosscultural Psychology, 31 (3), 283-301.

Misangyi, V.F., Acharya, A.G., 2014. Substitutes or complements? A configurational examination of corporate governance mechanisms. Academy of Management Journal, 57 (6), 1681-1705. 
Misangyi, V.F., Greckhamer, T., Furnari, S., Fiss, P.C., Crilly, D., Aguilera, R., 2016. Embracing causal complexity: the emergence of a neo-configurational perspective. Journal of Management, Forthcoming. DOI: 10.1177/0149206316679252

Monnet, C., Quintin, E., 2007. Why do financial systems differ? History matters. Journal of Monetary Economics, 54, 1002-1017.

Nakata, C., Sivakumar, K., 1996. National culture and new product development: an integrative review. Journal of Marketing, 60 (1), 61-72.

North, D.C., 1990. Institutions, Institutional Change and Economic Performance. Cambridge, Cambridge University Press.

OECD., 2010. PISA 2009 results: Overcoming social background: Equity in learning opportunities and outcomes (Volume II). Retrieved from http://dx.doi.org/10.1787/9789264091504-en Accessed on [15-Sept-2014].

OECD., 2014. Do countries with high mean performance in PISA maintain their lead as students age? PISA in Focus. OECD Publishing, Paris.

Peng, M.W., Wang, D.Y., Jiang, Y., 2008. An institution-based view of international strategy: a focus on emerging markets. Journal of International Business Studies, 39 (5), 920-936.

Pontusson, J., Swenson, P., 1996. Labor markets, production strategies and wage bargaining institutions. Comparative Political Studies, 29 (2), 223-250.

Porter, M.E., 1990. The Competitive Advantage of Nations. New York: The Free Press.

Quinn, J., 1979. Technological innovation, entrepreneurship and strategy. Sloan Management Review, 20 (3), 19-30.

Ragin, C., 2008. Redesigning Social Inquiry: Fuzzy Sets and Beyond. Chicago, US: University of Chicago Press.

Ralston, D.A., 2008. The crossvergence perspective: reflections and projections. Journal of International Business Studies, 39 (1), 27-40.

Ralston, D.A., Gustafson, D.J., Cheung, F., Terpstra, R.H., 1993. Differences in managerial values: a study of US, Hong Kong and PRC managers. Journal of International Business Studies, 24 (2), 249-275.

Ralston, D.A., Holt, D. A., Terpstra, R. H., Yu, K. C., 1997. The impact of national culture and economic ideology on managerial work values: a study of the United States, Russia, Japan, and China. Journal of International Business Studies, 28 (1), 177-208.

Rao, A. N., Pearce, J. L., Xin, K., 2005. Governments, reciprocal exchange and trust among business associates. Journal of International Business Studies, 36 (1), 104-118. 
Rinne, T., Steel, G. D., Fairweather, J., 2012. Hofstede and Shane revisited: the role of power distance and individualism in national-level innovation success. Cross-Cultural Research, 46 (2), 91-108.

Riordan, M., 2005. No monopoly on innovation. Harvard Business Review, 83 (12), 18-20.

Ronen, S., Shenkar, O., 2013. Mapping world cultures: cluster formation, sources and implications. Journal of International Business Studies, 44 (9), 867-897.

Rothberg, R.R., 1995. National innovation systems: a comparative analysis : by Richard R. Nelson, Editor. New York: Oxford University Press, 1993. $541+$ x pages. Journal of Product Innovation Management, 12 (1), 94-95.

Samara, E., Georgiadis, P., Bakouros, I., 2012. The impact of innovation policies on the performance of national innovation systems: a system dynamics analysis. Technovation, $32,624-638$.

Senker, J., 1996. National systems of innovation, organization, and learning in industrial biotechnology. Technovation, 16 (5), 219-229.

Schneider, M.R., Paunescu, M., 2012. Changing varieties of capitalism and revealed comparative advantages from 1990 to 2005: a test of the Hall and Soskice claims. SocioEconomic Review, 10 (4), 731-753.

Schneider, M.R., Schulze-Bentrop, C., Paunescu, M., 2010. Mapping the institutional capital of high-tech firms: a fuzzy-set analysis of capitalist variety and export performance. Journal of International Business Studies, 41 (2), 246-266.

Seo, M-G., Creed, W.E.D., 2002. Institutional contradictions, praxis, and institutional change: a dialectical perspective. Academy of Management Review, 27 (2), 222-247.

Shane, S.A., 1992. Why do some societies invent more than others? Journal of Business Venturing, 7 (1), 29-46.

Shane, S.A., 1993. Cultural influences on national rates of innovation. Journal of Business Venturing, 8 (1), 59-73.

Shane, S.A., 1995. Uncertainty avoidance and the preference for innovation championing roles. Journal of International Business Studies, 26 (1), 47-68.

Shim, T.Y., 2011. Korean Entrepreneurship: The Foundation of the Korean Economy. New York: Palgrave Macmillan.

Taylor, M.Z., Wilson, S., 2012. Does culture still matter? The effects of individualism on national innovation rates. Journal of Business Venturing, 27 (2), 234-247.

Vertova, G., 2001. National technological specialisation and the highest technological opportunities historically. Technovation, 21, 605-612. 
Visser, J., 2013. ICTWSS: Database on Institutional Characteristics of Trade Unions, Wage Setting, State Intervention and Social Pacts in 34 countries between 1960 and 2012. http://stats.oecd.org/OECDStat_Metadata/ShowMetadata.ashx?Dataset=UN_DEN. Accessed on [02-Sept-2014]

WEF (World Economic Forum). 2010. The Global Competitiveness Report 2010-2011. World Economic Forum, Geneva.

Whitley, R., 1992. European Business Systems: Firms and Markets in Their National Contexts. London: Sage.

Whitley, R., 1999. Divergent Capitalisms: The Social Structuring and Change of Business Systems. Oxford: Oxford University Press.

Whitley, R., 2007. Business Systems and Organizational Capabilities: The Institutional Structuring of Competitive Competences. Oxford: Oxford University Press.

WIPO (World Intellectual Property Organization). 2014. World Intellectual Property Indicators. WIPO-Economics \& Statistics Series, Geneva.

Witt, M.A., 2008. Crossvergence 10 years on: impact and further potential. Journal of International Business Studies, 39 (1), 47-52.

Witt, M.A., Redding, G., 2009. Culture, meaning, and institutions: Executive rationale in Germany and Japan. Journal of International Business Studies, 40 (5), 859-885.

Zhang, W., Yang, X. L. 2006. Roles and positioning of higher education institutions and research institutes in national innovation system. $R \& D$ Management, 18 (4), 97-103. 
Table 1: Measurement and Calibration

\begin{tabular}{|c|c|c|c|c|c|c|c|c|}
\hline \multirow{2}{*}{ Type } & \multirow{2}{*}{ Variable } & \multirow{2}{*}{ Measurement \& Data Source } & \multirow{2}{*}{$\begin{array}{l}\text { Calibration } \\
\text { Anchors (04- } \\
\text { 05/10-11) }\end{array}$} & \multirow{2}{*}{$\begin{array}{l}\text { Fuzzy } \\
\text { Sets }\end{array}$} & \multicolumn{4}{|c|}{ Measure Descriptives (04-05/10-11) } \\
\hline & & & & & Mean & SD & Max & Min \\
\hline \multirow{2}{*}{ Outcome } & \multirow{2}{*}{$\begin{array}{l}\text { Revealed } \\
\text { Innovation } \\
\text { Specialization } \\
\text { (RIS) }\end{array}$} & $\begin{array}{l}\text { Proxied by Balassa index of RIS in biotechnology, } \\
\text { nanotechnology, and information and communication }\end{array}$ & $0,0.57,0.82,1.08$ & \multirow{2}{*}{4} & 0.78 & 0.31 & 1.44 & 0.21 \\
\hline & & $\begin{array}{l}\text { OECD/EPO patent database, based on Hotho's (2014) } \\
\text { measurement of innovation specialization. }\end{array}$ & $0,0.59,0.82,1.04$ & & 0.82 & 0.27 & 1.34 & 0.31 \\
\hline \multirow{8}{*}{$\begin{array}{l}\text { Culture } \\
\text { Indicators }\end{array}$} & \multirow{2}{*}{$\begin{array}{l}\text { Uncertainty } \\
\text { Avoidance }\end{array}$} & \multirow{2}{*}{$\begin{array}{l}\text { Uncertainty avoidance index of national culture, } \\
\text { adopted from Hofstede (1980), and Hofstede, Hofstede, } \\
\text { \& Minkov (2010) }\end{array}$} & \multirow{2}{*}{$5,50,95$} & \multirow{2}{*}{3} & 64.65 & 24.69 & 112 & 23 \\
\hline & & & & & 65.83 & 22.00 & 100 & 23 \\
\hline & \multirow{2}{*}{ Masculinity } & \multirow{2}{*}{$\begin{array}{l}\text { Masculinity index of national culture, adopted from } \\
\text { Hofstede (1980), and Hofstede, Hofstede, \& Minkov } \\
\text { (2010) }\end{array}$} & \multirow[b]{2}{*}{$5,50,95$} & \multirow[b]{2}{*}{3} & 50.30 & 23.91 & 95 & 5 \\
\hline & & & & & 52.17 & 25.15 & 100 & 5 \\
\hline & \multirow[b]{2}{*}{ Individualism } & \multirow{2}{*}{$\begin{array}{l}\text { Individualism index of national culture, adopted from } \\
\text { Hofstede (1980), and Hofstede, Hofstede, \& Minkov } \\
\text { (2010) }\end{array}$} & \multirow[b]{2}{*}{$5,50,95$} & \multirow[b]{2}{*}{3} & 64.96 & 19.03 & 91 & 27 \\
\hline & & & & & 62.73 & 19.06 & 91 & 18 \\
\hline & \multirow[b]{2}{*}{ Power Distance } & \multirow{2}{*}{$\begin{array}{l}\text { Power distance index of national culture, adopted from } \\
\text { Hofstede (1980), and Hofstede, Hofstede, \& Minkov } \\
\text { (2010) }\end{array}$} & \multirow[b]{2}{*}{$5,50,95$} & \multirow[b]{2}{*}{3} & 43.26 & 18.02 & 81 & 11 \\
\hline & & & & & 46.53 & 19.76 & 100 & 11 \\
\hline \multirow{2}{*}{$\begin{array}{l}\text { Institutional } \\
\text { Indicators }\end{array}$} & \multirow{2}{*}{ Union Density } & $\begin{array}{l}\text { Net union membership as a proportion of employed } \\
\text { wage and salary earners, based on Visser's (2013) }\end{array}$ & $15.6,25.2,34.8$ & & 31.35 & 20.57 & 76.9 & 7.8 \\
\hline & & $\begin{array}{l}\text { measure. Data are collected from ICTWSS Database 4.0, } \\
\text { April } 2013 \text {. }\end{array}$ & $15.6,26.1,36.6$ & & 28.93 & 20.61 & 79.4 & 5.9 \\
\hline
\end{tabular}


The percentage of variance in student performance attributable to differences among schools (intra-class correlation coefficient), based on Hotho's (2014)

Strength of Education System measure. Data are collected from OECD Programme for International Student Assessment (PISA) database 2000 and 2009. The OECD Programme for International Student Assessment (PISA) develops three-yearly surveys that examine 15-year-old students' performance in reading, mathematics, and science.

Market capitalization to GDP divided by private credit provided by deposit money banks to GDP, following

Market

Capitalization to

Credit

Prevalence of

Cluster

State Dominance obtained from the World Bank World Development Indicators \& Global Development Finance database 2011. Data on private credit by deposit money banks obtained from the World Bank Financial Structure dataset 2013 . pervasiveness of clusters, including research institutes and training providers, on a scale from 1 to 7 . Data are collected from Global Competitiveness Report 20042005 and 2010-2011. policies, and the degree of selectivity associated with
$36.3,24.85,13.4$

32.07

17.50

58

3

$46.1,32.3,18.5$

$0.6,0.995,1.4$

0.95

0.56

Following Hotho (2014), this variable is measured by the

A combined measure of the independence of government 
Table 2: Necessary Conditions ${ }^{\text {a }}$

\begin{tabular}{|c|c|c|c|c|}
\hline & \multicolumn{2}{|c|}{ RIS in Year $2011^{b}$} & \multicolumn{2}{|c|}{ RIS in Year $2005^{b}$} \\
\hline & Consistency & Coverage & Consistency & Coverage \\
\hline Uncertainty Avoidance & 0.70 & 0.57 & 0.69 & 0.55 \\
\hline Masculinity & 0.57 & 0.58 & 0.62 & 0.62 \\
\hline Individualism & 0.78 & 0.64 & 0.87 & 0.66 \\
\hline Power Distance & 0.53 & 0.64 & 0.50 & 0.63 \\
\hline Union Density & 0.51 & 0.67 & 0.64 & 0.67 \\
\hline Skill Development & 0.44 & 0.70 & 0.65 & 0.73 \\
\hline Market Capitalization to Credit & 0.39 & 0.59 & 0.47 & 0.63 \\
\hline Prevalence of Cluster & 0.51 & 0.66 & 0.74 & 0.72 \\
\hline State Dominance & 0.59 & 0.57 & 0.44 & 0.49 \\
\hline
\end{tabular}

Note: ${ }^{a}$ Necessary conditions are calculated with the fsQCA 2.5 software.

${ }^{\mathrm{b}} \mathrm{RIS}$ is calculated as 1 year time lag with casual conditions. 
Table 3: Configurations for RIS ${ }^{\text {a }}$

\begin{tabular}{|c|c|c|c|c|c|c|c|c|c|c|c|c|c|c|}
\hline \multirow[b]{2}{*}{ Configuration $^{c}$} & \multicolumn{7}{|c|}{ Solution for $2011^{b}$} & \multicolumn{7}{|c|}{ Solution for $2005^{b}$} \\
\hline & $\mathbf{I a}^{* *}$ & Ib** & IIc* & IId* & IIe* $^{*}$ & IIIf & IIIg & Ih** & $\mathbf{I i}^{* *}$ & $\mathbf{I I j}^{*}$ & IIk* & III* & IIIm & IIIn \\
\hline \multicolumn{15}{|l|}{ Culture Indicators } \\
\hline Uncertainty Avoidance & $\otimes$ & $\bullet$ & $\otimes$ & $\bullet$ & $\otimes$ & $\bullet$ & $\otimes$ & $\otimes$ & $\bullet$ & $\otimes$ & $\bullet$ & $\otimes$ & $\bullet$ & $\bullet$ \\
\hline Masculinity & $\otimes$ & $\bullet$ & $\bullet$ & $\otimes$ & $\bullet$ & $\otimes$ & $\bullet$ & $\otimes$ & $\bullet$ & $\bullet$ & $\otimes$ & $\bullet$ & $\otimes$ & $\bullet$ \\
\hline Individualism & $\bullet$ & $\bullet$ & $\bullet$ & $\bullet$ & $\bullet$ & $\bullet$ & $\bullet$ & $\bullet$ & $\bullet$ & $\bullet$ & $\bullet$ & $\bullet$ & $\bullet$ & $\otimes$ \\
\hline Power Distance & $\otimes$ & $\otimes$ & $\otimes$ & $\otimes$ & $\otimes$ & $\bullet$ & $\otimes$ & $\otimes$ & $\otimes$ & $\otimes$ & $\otimes$ & $\otimes$ & $\otimes$ & $\bullet$ \\
\hline \multicolumn{15}{|l|}{ Institutional Indicators } \\
\hline Union Density & $\bullet$ & $\otimes$ & $\bullet$ & $\bullet$ & $\bullet$ & $\otimes$ & $\otimes$ & $\bullet$ & $\otimes$ & $\bullet$ & $\bullet$ & $\bullet$ & $\otimes$ & $\otimes$ \\
\hline Skill Development & $\otimes$ & $\bullet$ & $\bullet$ & $\otimes$ & $\bullet$ & $\bullet$ & $\otimes$ & $\otimes$ & $\bullet$ & $\bullet$ & $\bullet$ & $\bullet$ & $\bullet$ & $\otimes$ \\
\hline Market Capitalization to Credit & $\bullet$ & $\bullet$ & $\otimes$ & $\otimes$ & $\otimes$ & $\otimes$ & $\bullet$ & $\bullet$ & $\bullet$ & $\otimes$ & $\bullet$ & & $\otimes$ & $\otimes$ \\
\hline Prevalence of Cluster & $\bullet$ & $\otimes$ & $\bullet$ & $\bullet$ & $\otimes$ & $\otimes$ & $\bullet$ & $\bullet$ & $\otimes$ & $\bullet$ & $\bullet$ & $\bullet$ & $\otimes$ & $\bullet$ \\
\hline State Dominance & $\otimes$ & $\otimes$ & $\otimes$ & $\otimes$ & $\bullet$ & $\bullet$ & $\bullet$ & $\otimes$ & $\otimes$ & & $\otimes$ & $\bullet$ & $\otimes$ & $\otimes$ \\
\hline Consistency & 0.94 & 1.00 & 1.00 & 1.00 & 0.95 & 0.96 & 0.99 & 1.00 & 1.00 & 0.99 & 1.00 & 1.00 & 1.00 & 1.00 \\
\hline Raw Coverage & 0.12 & 0.07 & 0.09 & 0.11 & 0.08 & 0.10 & 0.09 & 0.11 & 0.07 & 0.23 & 0.14 & 0.13 & 0.14 & 0.11 \\
\hline Unique Coverage & 0.06 & $\mathbf{0 . 0 3}$ & $\mathbf{0 . 0 3}$ & 0.04 & 0.05 & 0.05 & 0.04 & 0.04 & 0.04 & 0.05 & 0.05 & 0.01 & 0.07 & 0.05 \\
\hline Case Country & Sweden & Australia & UK & Finland & Ireland & Spain & US & Sweden & Australia & UK & Finland & Ireland & Netherlands & Japan \\
\hline Overall Solution Consistency & & & & 0.97 & & & & & & & 0.99 & & & \\
\hline Overall Solution Coverage & & & & 0.41 & & & & & & & 0.52 & & & \\
\hline
\end{tabular}

Note: a Following Ragin (2008), only intermediate solutions are reported.

b Black circles indicate the presence of a condition, and circles with "X" indicate its absence. Blank spaces indicate "don't care".

c**sign refers to the identical solutions between 2004 and 2010, while* sign means similar or compatible solutions between 2004 and 2010. 


\section{Appendix 1: Theoretical Background}

\section{A: The relationship between Hofstede's culture dimensions and national innovation}

Uncertainty avoidance concerns how societies cope with the unknown aspect of the future.

Hofstede (1980) adopts three key indicators to assess the dimension, namely, rule orientation, employment stability and stress, and he argues that uncertainty-accepting societies are more tolerant of changes and risk taking (often associated with innovative activities) than people in uncertainty-avoiding ones. However, empirical findings on the impact of uncertainty avoidance on innovation have been inconclusive. Shane $(1993,1995)$ finds evidence that an acceptance of uncertainty appears to be necessary for a nation to be innovative. Nevertheless, those findings do not indicate a clear relationship between uncertainty avoidance and the per capita rate of invention across societies (Shane, 1992). Neither is this evident in the empirical study by Rinne and colleagues (2012).

Masculinity, together with its opposite pole Femininity as the duality of the sexes, is related to "a fundamental fact with which different societies cope in different ways" (Hofstede, 1980: 176). A masculinity orientated culture values self-assertiveness, independence and career (such as achievement, promotion, and competition), as opposed to feminine values, that include relationships, modesty, tolerance, the quality of life and physical working conditions (Hofstede et al., 2010; Nakata \& Sivakumar, 1996). It has been argued that innovation is motivated by financial rewards, prestige, and a sense of accomplishment (Shim, 2011; Quinn, 1979). In 
masculine societies, the ambitious, assertive and risk-taking dominating societal values promote innovation and an entrepreneurship spirit (Shim, 2011). However, the empirical evidence has challenged this intuitive view. For instance, Shane (1993) demonstrated that masculinity has no effect on the number of trademarks per capita. Nakta and Sivakumar (1996) argue that those feminine societies focusing on "people" can provide a supportive climate, low conflict, trust and a socio-emotional support environment, all of which are critical for new ideas incubation and implementation.

Individualism is defined as a preference for a loosely-knit social structure in which individuals are expected to take care of only themselves and their immediate families (Hofstede et al., 2010). In Hofstede's (1980) original assessment, the measurement of individualism involves six aspects: freedom, a cosmopolitan orientation of a society, autonomy, reward incentives, goal achieving environment and psychological characteristics. Shane (1992, 1993) demonstrates that individualistic societies are more inventive and innovative than collectivistic ones, because these key values, such as freedom, an outward orientation and getting senior managers' support, can stimulate creativity. Rinne et al. (2012) also find that individualism is strongly and positively related to innovation, and the key values, such as autonomy, independence and freedom are requisite for a nation to be innovative. While supporting the significant role of individualism in national innovation, Taylor and Wilson (2012) also point 
out that collectivism, in certain situations (e.g., as part of patriotism or nationalism) can have an almost as strong positive effect as individualism on innovation rates.

Power distance refers to the extent to which society members create the unequal distribution of power in organisations. Hofstede (1980) argues that human inequality is inevitable and functional in each organisation and society. Inequality is reflected in how different societies have found solutions to deal with attitudes towards prestige, wealth and power. Hofstede's (1980) power distance index (PDI) adopts seven key measures: the desirability of hierarchy, information communication, centralization, control over subordinates, detailed instruction to subordinates, fatalism or weak work ethic, and the unwillingness of accept change in power distribution. Previous studies generally take the view that lower PDI societies encourage innovation at the organisational level than do higher PDI ones. In Bessant and Grunt's (1985) study, successful innovation in both British and German manufacturing firms is associated with shared responsibilities and consultative management decision-making process. By examining data on the per capita number of trademarks granted to nationals of 33 countries in the US and world markets in 1975 and 1980, Shane (1993) concludes that less power-distant societies are more innovative than more power-distant societies. The finding is also supported by Rinne et al. (2012), who adopted the Global Innovation Index (GII) as the measurement of national innovation. 


\section{B: The relationship between comparative institutional dimensions and national innovation}

Union Density refers to net union membership as a proportion of employed wage and salary earners, which can capture the strength of independent trade unions (Visser, 2013). Based on the comparative institutional perspective, high employment protection (e.g., strong barriers to or high cost of dismissing employees through the termination of employment contracts) characterises CME countries, but not LME countries (Whitley, 1998, 1999). Employment protection against dismissal in bad faith is necessary to effectively motivate and nurture innovation. For instance, in studying wrongful dismissal laws in the US and their impact on innovation, Acharya, Baghai and Subramanian (2012) argue that employment protection practices and regulations, particularly those that protect employees from termination in bad faith, foster innovation. Manso (2011) suggests that employment contracts that tolerate failure (in other words, provide protection in case of failure) in the short run and maintain job security and reward success in the long run best motivate innovation. Among others, empirical studies show that the presence of strong unions and centralized wage bargaining is one of the paths toward high innovation performance (e.g., Hotho, 2014), and lax employment protection does not appear to be an important feature in contributing to the export performance of high-tech sectors (e.g., Schneider et al., 2010).

Skill Development refers to the skill training and education system that aims to generate high-quality human resources, especially scientific, technical and managerial personnel. An 
educational system can secure a continuous supply of scientists - a crucial resource for companies in a high-technology industry (Schneider et al., 2010). Furman, Porter and Stern (2002: 904) point out that "without skilled scientists and engineers operating in an environment with access to cutting-edge technology, it is unlikely that a country will produce an appreciable amount of new-to-the-world innovative output". Moreover, the considerable international variation in the skill development system (including both general and specific skill training) is attributable to the differences in $\mathrm{R} \& \mathrm{D}$ manpower as inputs in the innovation process (Furman et al., 2002).

Market Capitalization to Credit is a ratio of market capitalization to GDP divided by the ratio of private credit extended by deposit money banks to GDP (Hotho, 2014). It reflects the relative importance of two distinct sources of capital in the financial systems: firms' dependence on bank loans and the use of the stock market (Monnet \& Quintin, 2007). A fluid stock market diversifies risks, which is often considered to be a precondition for national systems of innovation (Schneider et al., 2010). Also, an ample supply of risk-tolerance capital is a determinant of national innovation capacity building, because the availability of risk capital can translate scientific and technological outputs into economic opportunities for further innovation and commercialization (Furman et al., 2002). The comparative institutional perspective suggests that that reliance on stock market (i.e., equity) is a more dominant feature 
in LME countries, while firms originating from CME countries rely more on bank financing (i.e., debt) (Schneider et al., 2010).

Prevalence of Clusters creates agglomeration economies, which lead to network externalities, and which, in turn, generate spatial concentration of particular value-added activities within specific locales (Porter, 1990). Porter (1990) argues that clusters have the potential to affect competition in three ways: by driving innovation in the field, by increasing the productivity of the companies in the cluster, and by stimulating new businesses in the field. Cluster development has since become a focus for many government programs. However, although industry clusters (such as Silicon Valley in the US, and Digital Media City in South Korea) and intermediary associations can promote significant collaborating effects on innovation and foster regional economic development, they also increase entry barriers to a particular industry or regional economy, and to some extent they demotivate free market competition (Krugman, 1991). Therefore the state's tolerance of cluster development and intermediate associations between the state and firms is one of the most important aspects of the state in influencing different forms of economic organizations (Whitley, 1999).

State Dominance refers to the strength of the state in relation to special-interest groups and the role of the state in the development of economic activity (Hotho, 2014; Whitley, 1999). The impact of the state can be traced back to the early stage of the comparative institutional perspective (Hall \& Soskice, 2001; Whitley, 1999). The strength of the state in relation to 
special-interest groups is captured in the independence of government policies from special interest groups, while the role of the state in the development of economic activity is embedded in the extent to which government subsidies promote fair competition (Hotho, 2014). State dominance has an impact on the national innovation system (Freeman, 1995; Lundvall, 2007; Samara, et al., 2012). For example, as Landes has said (1970: 151), "the government provided technical advice and assistance, awarded subventions to inventors and immigrant entrepreneurs, bestowed gifts of machinery, allowed rebates and exemptions of duties on imports of industrial equipment". In addition, it is commonly recognized that monopolies stifle innovation, because the lack of competition consolidates and protects a company's dominant market position, rather than encouraging the creation of revolutionary products and services (Riordan, 2005). Therefore, the effectiveness of anti-trust policy and non-favoritism in governance decisions are crucial to create an encouraging environment for national innovation system. 